\title{
Broad Beam and Gamma Spectrometric Parameters of Some Granites
}

\author{
Abdul-Hamid Hussein El-Kateb, Asmaa Sophy Seif EL-Nasr, Mahmoud Mohamed Bakry \\ Faculty of Science, Helwan University, Helwan, Cairo, Egypt \\ Email address: \\ mm721381@gmail.com (M. M. Bakry)

\section{To cite this article:} \\ Abdul-Hamid Hussein El-Kateb, Asmaa Sophy Seif EL-Nasr, Mahmoud Mohamed Bakry. Broad Beam and Gamma Spectrometric \\ Parameters of Some Granites. Radiation Science and Technology. Vol. 5, No. 4, 2019, pp. 47-52. doi: 10.11648/j.rst.20190504.13
}

Received: October 3, 2019; Accepted: October 31, 2019; Published: November 7, 2019

\begin{abstract}
Using a $\gamma$-ray spectrometer with 3"x3" NaI (Tl) detector the linear and mass attenuation coefficients $(\mu / \rho)$ and $\left(\mu_{\mathrm{b}} / \rho\right)$ from narrow and broad beam experimental arrangements have been measured and compared with the theoretical values for the granites Double Black, DB, from India, Rose Al-Howdy, RH, from Aswan, south Egypt and Bianco Halayeb, BK, from Halayeb, south Egypt. The photon energies lei in the range $0.081-1.332 \mathrm{MeV}$ from the radioisotopes ${ }^{133} \mathrm{Ba},{ }^{137} \mathrm{Cs}$ and ${ }^{60} \mathrm{Co} . \mathrm{The}$ build-up factor $\mathrm{B}$, the effective atomic number $\mathrm{Z}_{\mathrm{eff}}$, and the total atomic cross-section $\sigma_{\mathrm{t}}$ for the granites as a function of photon energy were determined and discussed. It is found that the experimental results are consistent, within the experimental errors, with the theoretical values. The effective atomic number $Z_{\text {eff }}$, the build-up factor $\mathrm{B}$, and the total atomic cross-section $\sigma_{\mathrm{t}}$ were calculated and discussed as a function of photon energy. The B factor is large at low gamma energy and not sensitive for discrimination between the granites. The maximum $Z_{\text {eff }}$ corresponds to minimum $\mathrm{B}$ factor at the photon energy $0.356 \mathrm{MeV}$. The broad beam geometry is more efficient than narrow beam geometry in characterizing the shielding properties of the studied granites.
\end{abstract}

Keywords: Gamma-ray Spectrometry, Radiation Protection, Mass Attenuation Coefficients, Build-up Factor, Effective Atomic Number, Total Atomic Cross-section

\section{Introduction}

Everything in our environment is exposed to ionizing radiation from different sources like radioactive materials and cosmic radiation. Efforts are undertaken to possibly reduce the resulting harms. Protection against hazards of gamma radiation is of absolute mandatory. Therefore, studies and investigations are conducted to measure and evaluate the gamma spectrometric quantities of materials used in many fields as industry, medicine, biology, dosimetry, shielding, ...etc. Granite and basalt are used as shielding and building materials owing to the massive nature and homogeneous grains. Granite is eminently adapted for monumental and architectural work as well as for massive masonries. The linear and mass attenuation coefficients from narrow and broad radiation beams, respectively $(\mu),\left(\mu_{b}\right)$ and $(\mu / \rho),\left(\mu_{b} / \rho\right)$, the build-up factors $B$, the effective atomic numbers $Z_{\text {eff }}$ and the total atomic cross-section, $\sigma \mathrm{t}$, are proudly used parameters in this respect.[1-3] The trend of $Z_{\text {eff }}$ with respect to the energy inverts from decrease to increase and vice versa according to the ranges of photon energy and the atomic number of the material. [4-6] Organic nonlinear optical materials of $Z_{\text {eff }}$ in the range 3-5 follow slight decrease with $E_{\gamma}$ from 0.122 to $1.332 \mathrm{MeV}$. [6] Expressions for $Z_{\text {eff }}$ in the photo-electric, the Compton and the pair production regions in terms of the atomic numbers in a composite material were proposed and applied. [7] Values of $Z_{\text {eff ph }}, Z_{\text {eff Compton }}$ and $Z_{\text {eff pair, were reported for each material }}$ and each energy under study. The photon attenuation by matter at the energy range below $100 \mathrm{keV}$ is prevailed by the photo-electric effect. The cross-section for this process is proportional to the atomic number of the attenuator and the gamma energy according to the relation $\left(Z^{n} / E_{\gamma}{ }^{m}\right), n$ and $m$ vary from 3 to 5 . The Compton interaction prevails at the energy range $0.1-1 \mathrm{MeV}$ this interaction is proportional to the atomic number of the material. At energies $\geq 1.022 \mathrm{MeV}$ interaction between photons and the material atoms by pair production shares with the Compton scattering, furthermore its probability appreciably ascends with energy besides the square of the atomic number. If there is no good collimation 
of beam-area exposure, significant dose will consequently be absorbed, where impact of single and multiply scattered photons is possible. Radiation absorption characteristics of rocks collected from Jeddah, Mecca, Mina, and Taif areas have been studied. Most of the rocks show higher radiation attenuation than standard concrete. Only granites were found to be equivalent to concrete. [8] The linear and mass attenuation coefficients of gamma rays transmitted through granites of different countries were studied in the energy range 0.081-1.332 MeV. [9] It was concluded that the linear attenuation coefficients are appropriately correlated with the material density. Moreover, the mass attenuation coefficients are larger for materials of large atomic numbers. Various Turkish granites and marble spices were investigated via measuring $(\mu),(\mu / \rho)$ the half value layer and the tenth value layer, at the energy region $80.99 \mathrm{keV}$ to $1.332 \mathrm{MeV}$ using HPGe detector, the results were compared with literature. [10] The density of hydrous peridotite magma containing 5\% wt. $\mathrm{H} 2 \mathrm{O}$ was measured at pressures and temperatures up to 4.3 GPa and 2073-degree $\mathrm{K}$, respectively, using the X-ray absorption method. [11] The transmission of X-rays in the energy range $0.081-1.332 \mathrm{MeV}$ was studied on alloys brass, bronze, steel, aluminum-silicon, and lead-antimony. The mass attenuation coefficients were measured, the atomic cross-sections and the effective atomic numbers were determined. [4] The shielding parameters of rocks and concrete were studied in the energy range $0.122-1.332 \mathrm{MeV}$. [12] The results showed that feldspathic basalt, volcanic rock dolerite, and pink granite are more efficient than sandstone and concrete for gamma-ray shielding applications. The effect of scattered photons on the accuracy of measured $(\mu / \rho)$ for low Z-building materials was investigated. [13] It was concluded that good accuracy in $(\mu / \rho)$ measurement can be achieved if the absorber optical thickness does not exceed 0.5 the mean free path. The shielding properties of granites which are produced in Turkey were studied for linear and mass attenuation coefficients of gamma rays at the energies $0.611,1.173$ and $1.332 \mathrm{MeV}$ using $\mathrm{NaI}(\mathrm{Tl})$ detector. [14] The measurements were carried out in narrow and broad beam geometries. It was concluded that the highest linear attenuation coefficient belongs to Canakkale Grey, Giresun Vison and Akasari Pink at 0.662, 1.173 and $1.332 \mathrm{MeV}$ respectively while Bergama Grey has the lowest values. The experimental results are close to the values computed by XCOM code. [15]

In the present study $(\mu)$ and $(\mu / \rho)$ were measured from narrow and broad beam geometries for the Egyptian granite types Bianco Halayeb, and Rose El-Howdy, Aswan, and Indian Double Black granite at the energies 0.081, 0.356, $0.662,1.173$ and $1.332 \mathrm{MeV}$. These types of granites are widely used as materials for building and decoration. The results were compared with theoretical values. Comparisons between the granites besides the narrow and broad beam geometries were also undertaken via evaluation of the buildup factor $\mathrm{B}$, the effective atomic number $\mathrm{Z}_{\text {eff }}$ and the total atomic cross-section $\sigma_{t}$.

\section{Theoretical}

When the narrow (parallel) beam of $\gamma$ or X-rays transmitted through a material, attenuation by absorption and/or scattering occurs. The relation between the incident and scattered photons is described by the relation,

$$
I=I_{0} e^{-(\mu / \rho) t}
$$

$I_{0}$ and $I$ are the un-attenuated and attenuated photon intensities. $\rho$ and $t$ are respectively the density and thickness of the material, see figure 1 . By revealing the collimator between the source and the detector, the set-up is applied as broad beam (or open-angle) geometry. The build-up in scattered intensity can be expressed as

$$
B=\frac{I_{b}}{I}=e^{\left[(\mu / \rho)-\left(\mu_{b} / \rho\right)\right] t}
$$

$I_{b}$ stands for the broad beam intensity measured at the same conditions. The B factor comprises the mutual effects originated from the experimental arrangement, the attenuating material, (density, atomic number, etc.) and the energy of the incident photons.

The effective atomic number $Z_{\text {eff }}$ is the ratio between the atomic and electronic cross-sections. It is used to describe the properties of composite material in terms of $(\mu / \rho)$ and its constituents. It obeys the relation stated in [16].

$$
Z_{\text {effexp }}=\frac{(\mu / \rho)_{\text {Granite }} \sum_{i} f_{i} A_{i}}{\sum_{i} f\left(A_{i} / Z_{i}\right)\left(\mu_{i} / \rho\right)}
$$

In this regard, $Z_{\text {eff th }}$ can be determined from the expression,

$$
Z_{\text {eff th }}=\frac{(\mu / \rho)_{t h} \sum_{i} f_{i} A_{i}}{\sum_{i} f_{i}\left(A_{i} / Z_{i}\right)\left(\mu_{i} / \rho\right)}
$$

Where $\mathrm{f}_{\mathrm{i}}=\mathrm{n}_{\mathrm{i}} / \sum_{\mathrm{j}} \mathrm{n}_{\mathrm{j}}$, and $\left(\mu_{i} / \rho\right)$ represent respectively the fractional abundance and mass attenuation coefficient of the $i^{\text {th }}$ element in the attenuator. The effective atomic numbers $Z$ eff for the attenuators used have been calculated based on the $\mathrm{XCOM}$ results.

The total atomic cross-section $\sigma_{\mathrm{t}}$ obeys the formula, [17]

$$
\sigma_{t}=\frac{\left(\mu_{n} / \rho\right)_{\text {Granite }}}{N_{A} \sum_{i}\left(w_{i} / A_{i}\right)}
$$

$\mathrm{N}_{\mathrm{A}}$ is the Avogadro's number,

$\mathrm{W}_{\mathrm{i}}$ and $\mathrm{A}_{\mathrm{i}}$ are respectively the weight fraction and the mass number of the element $\mathrm{i}$.

Error calculation

The errors in $(\mu / \rho)$ and $Z_{\text {eff }}$ in terms of the measured values are calculated according to the following expressions

$$
(\Delta \mu / \rho)=(1 / t)\left\{\left(\Delta I_{0} / I_{0}\right)^{2}+(\Delta I / I)^{2}+\left[\ln \left(I_{0} / I\right)\right]^{2}(\Delta t / t)^{2}\right\}^{\frac{1}{2}}
$$

$\Delta I_{0}$ and $\Delta I$ are the standard deviations of the number of counts without and with the material. [18] The errors are less than $6 \%$.

The error in the $\sigma_{\mathrm{t}}$ obeys the relation, [4] 


$$
\begin{array}{r}
\Delta \sigma_{t}=\frac{\left(\Delta \mu_{n} / \rho\right)_{\text {Granite }}}{N_{A} \sum_{i}{ }^{W_{i}} / A_{i}} \\
\Delta Z_{\text {eff }}=\frac{(\Delta \mu / \rho)_{\text {Granite }} \sum_{i} f_{i} A_{i}}{\sum_{i} f_{i}\left(A_{i} / Z_{i}\right)(\mu / \rho)_{i}}
\end{array}
$$

\section{Materials and Methods}

The $\gamma$-ray spectrometer consists of 3"x3" NaI (Tl) detector attached to 1024 channel analyzer. The experimental set-up is illustrated in figure 1 . The gamma line $1.463 \mathrm{MeV}$ from ${ }^{40} \mathrm{~K}$ was employed as a natural monitor to ensure detection stability. The linear and mass attenuation coefficients $(\mu)$ and $(\mu / \rho)$ are measured at the energies $0.081,0.356$ from ${ }^{133} \mathrm{Ba}$, $0.662 \mathrm{MeV}$ from ${ }^{137} \mathrm{Cs}$ and $1.173,1.332 \mathrm{MeV}$ from ${ }^{60} \mathrm{Co}$. The granites studied are basalt- peridotite granite, (double black, DB) from India, alkali feldspar (Rose Al-Howdy, RH) from Aswan and Tonalite from Halayeb (Bianco Halayeb, BH). Halayeb and Aswan exist in the southern province of Egypt. The densities and thicknesses of the DB, RH, and $\mathrm{BH}$ sheets are respectively, $\left(3.1 \mathrm{gcm}^{-3}, 1.9 \mathrm{~cm}\right),\left(2.56 \mathrm{gcm}^{-3}, 1.8 \mathrm{~cm}\right)$ and $\left(2.66 \mathrm{gcm}^{-3}, 1.85 \mathrm{~cm}\right)$. The activities of the $\gamma$-sources ${ }^{137} \mathrm{Cs}$ and ${ }^{60} \mathrm{Co}$ are 580 and $180 \mu \mathrm{Ci}$ respectively. The sourcedetector distance is $50 \mathrm{~cm}$. In the case of ${ }^{133} \mathrm{Ba}$ this distance was reduced to $13 \mathrm{~cm}$. The broad beam measurements were performed with only the collimators around the source and the detector.

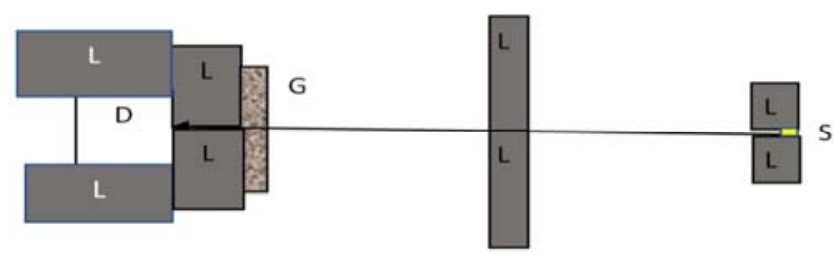

S, Source, D, Detector, G, granite, L, Lead Shield.

Figure 1. The experimental set-up.

The results of the mass attenuation coefficients were measured in narrow and broad beam geometries and indicated as $(\mu / \rho)$ and $\left(\mu_{b} / \rho\right)$ respectively. The results were compared with the values obtained from the theoretical XCOM program [15] according to a worldwide average of the chemical composition of 2485 granites, see table 1. [19] Other references do not show significant differences from this chemical composition. i), [20,21].

Table 1. The Chemical composition of granites.

\begin{tabular}{ll}
\hline $\mathrm{SiO}_{2}$ & $72.04 \%$ (silica) \\
$\mathrm{Al}_{2} \mathrm{O}_{3}$ & $14.42 \%$ (alumina) \\
$\mathrm{K}_{2} \mathrm{O}$ & $4.12 \%$ \\
$\mathrm{Na}_{2} \mathrm{O}$ & $3.69 \%$ \\
$\mathrm{CaO}$ & $1.82 \%$ \\
$\mathrm{FeO}$ & $1.68 \%$ \\
$\mathrm{Fe}_{2} \mathrm{O}_{3}$ & $1.22 \%$ \\
$\mathrm{MgO}$ & $0.71 \%$ \\
$\mathrm{TiO}_{2}$ & $0.30 \%$ \\
$\mathrm{P}_{2} \mathrm{O}_{5}$ & $0.12 \%$ \\
\hline
\end{tabular}

wydawnictwo.panova.pl/attachments/article/598/R27.pdf.
The corresponding elemental composition according to $\mathrm{XCOM}$ program is given in Table 2.

Table 2. The elemental analysis of granite.

\begin{tabular}{ll}
\hline Element & Fraction by Weight \\
\hline$Z=8$ & 0.484913 \\
$Z=11$ & 0.027454 \\
$Z=12$ & 0.004294 \\
$Z=13$ & 0.076540 \\
$Z=14$ & 0.337720 \\
$Z=19$ & 0.034302 \\
$Z=20$ & 0.013045 \\
$Z=26$ & 0.021733 \\
\hline
\end{tabular}

\section{Results and Discussion}

\subsection{The Linear and Mass Attenuation Coefficients}

The values of $\left(\mu_{b}\right),(\mu)$ as a function of $E_{\gamma}$ for all granites are plotted in figure 2 . Figures 3-5 show $\left(\mu_{b}\right),(\mu)\left(\mu_{b} / \rho\right)(\mu / \rho)$ and $\left(\mu_{\mathrm{th}} / \rho\right)$ as a function of energy for all granites. It is obvious from the figures that the attenuation coefficients decrease with increasing photon energies. Generally, there is good agreement between the experimental and theoretical values of the mass attenuation coefficients. It is clear that $\mu_{\mathrm{b}}$ and $\mu$ at $\mathrm{DB}>\mathrm{BH}>\mathrm{RH}$ for all photon energies. The high density of BD let its $\left(\mu_{b} / \rho\right)$ becomes less than $\left(\mu_{b} / \rho\right)$ for each of BH and $\mathrm{RH}$. The $(\mu / \rho)$ values are comparable for the three granites. Consequently, $(\mu)$ can provide clearer discrimination between granites, as a shielding material, than $(\mu / \rho)$, see also [9] and [14]. This can be correlated with the atomic numbers of the constituting atoms and the experimental set-up. The photo-electric effect is proportional to $Z^{n} / E_{\gamma^{3.5}, \mathrm{n}=4-5}$. The Compton interaction is proportional to $\mathrm{Z}$ and the pair production is proportional to $Z^{2} f\left(E_{\gamma}, Z\right)$.

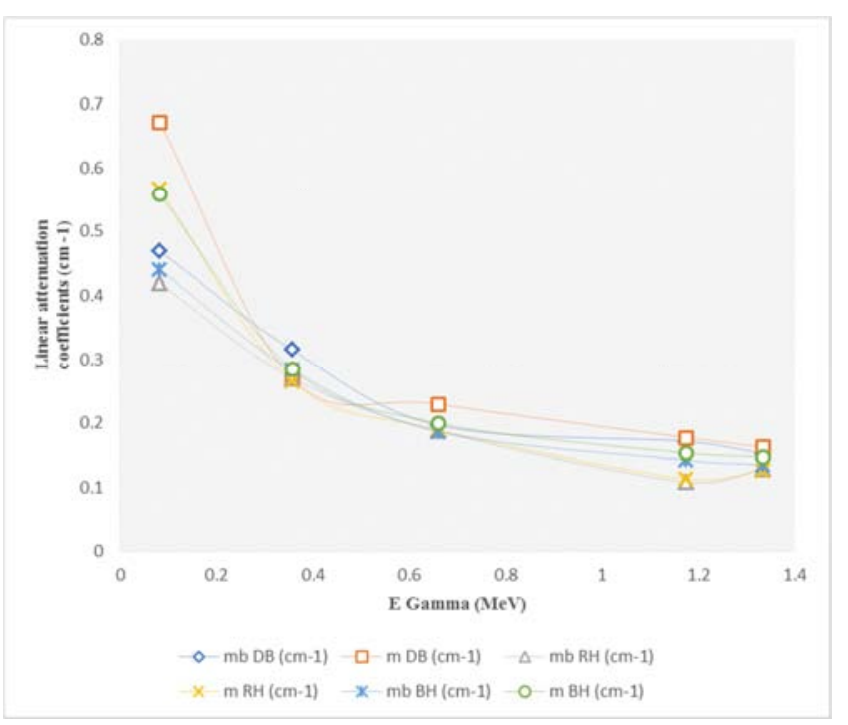

Figure 2. Linear narrow and broad beam attenuation coefficients for Double Black, Rose Al-Howdy and Bianco Halayeb granites. 


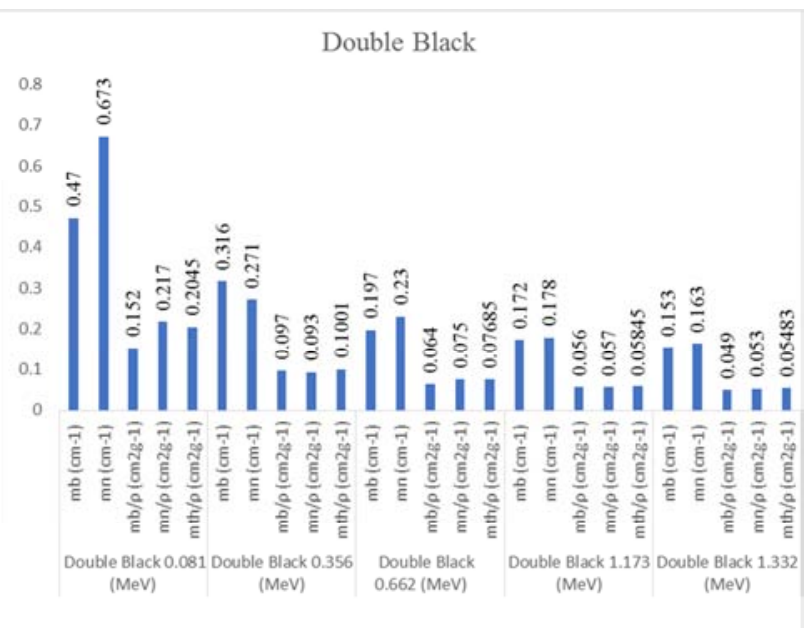

Figure 3. Linear and mass attenuation coefficients for broad and narrow beam geometries for Double Black granite.

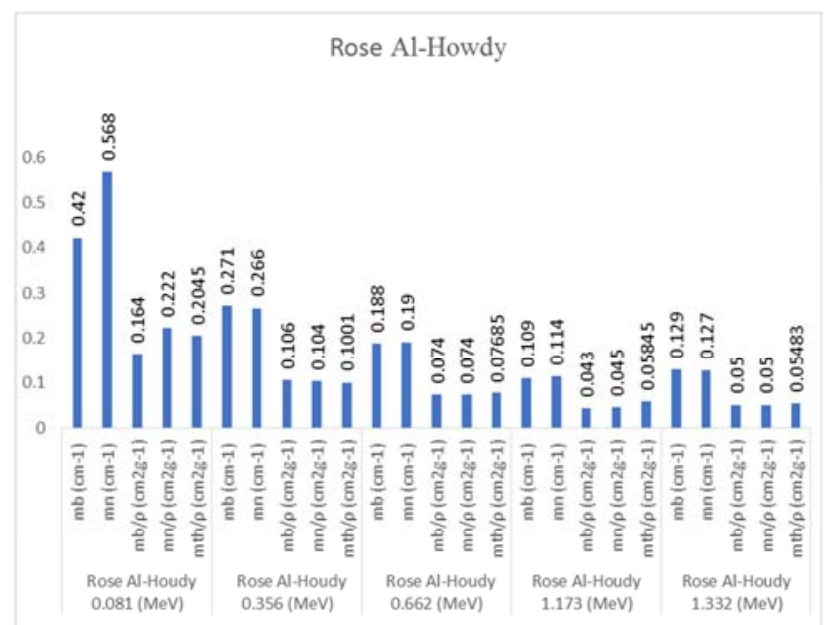

Figure 4. Linear and mass attenuation coefficients for broad and narrow beam geometries for Rose Al-Howdy granite.

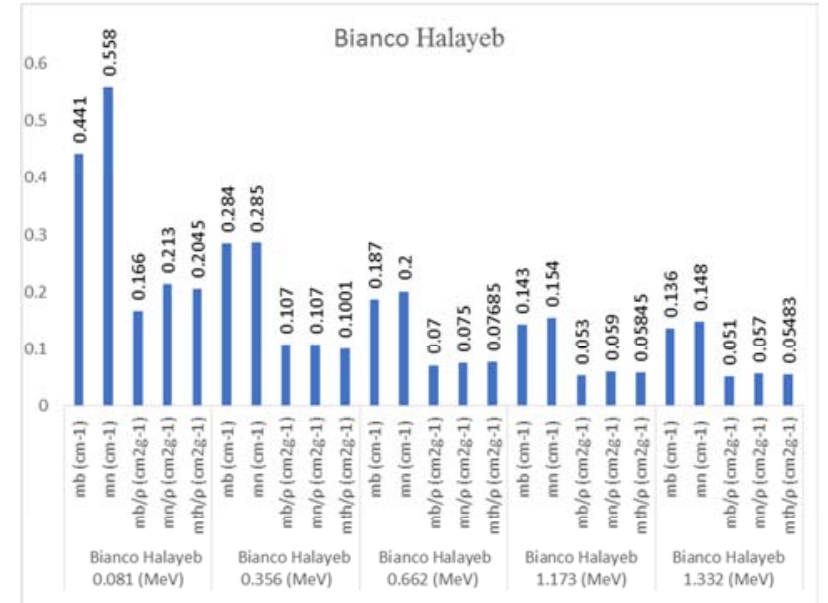

Figure 5. Linear and mass attenuation coefficients for broad and narrow beam geometries for Bianco Halayeb granite.
At the photon energies 0.081 and $0.662 \mathrm{MeV}$ the linear attenuation coefficients $(\mu)$ for $\mathrm{DB}=0.673$ and $0.23 \mathrm{~cm}^{-1}$ respectively. These values are comparable with $(\mu)$ of metabasalt (density $=2.98 \mathrm{gcm}^{-3}$ ) which are respectively 0.7513 and $0.216 \mathrm{~cm}^{-1}$ at these two energies. [8] Furthermore, the metabasalt and the DB in the present study have the largest values of $(\mu)$ in the rocks and granites studied. According to the values of $(\mu)$ and $(\mu / \rho)$, the DB granite is suggested as the best shielding material, at $\mathrm{E}_{\gamma}<0.3(\mathrm{MeV})$, while the $\mathrm{RH}$ and $\mathrm{BH}$ granites have nearby shielding properties. It might be of benefit to indicate that the values of $(\mu)$ at photon energies $0.662,1.173$ and $1.332 \mathrm{MeV}$ for Turkey granites lei in the ranges $0.148-0.341,0.133-0.168$, $0.129-0.158 \mathrm{~cm}^{-1}$ respectively. [14] To interpret for the large decrease of the attenuation coefficients from 0.081 to 0.356 $\mathrm{MeV}$ and smaller decrease at larger energies the ratio of attenuation by photo-electric effect to Compton scattering at $\mathrm{E}_{\gamma}=0.81,0.356,0.662,1.173$ and $1.332 \mathrm{MeV}$ is respectively $\cong 3.86 \times 10^{-1}, 3.96 \times 10^{-3}, 9.8 \times 10^{-4}, 3.69 \times 10^{-4}$ and $3.16 \times 10^{-4}$ and the ratio of attenuation by pair production to Compton scattering at $1.332 \mathrm{MeV}$ is also $\cong 10^{-3}$. [15, 19] It is obvious that the contribution of the photo-electric effect to the total mass attenuation coefficient is significant at the energy 0.081 $\mathrm{MeV}$ and appreciably decreases at larger energies. This can also be employed to interpret the changes of the total atomic cross-sections $\sigma_{t}$, see section 4 , from the energy $0.081 \mathrm{MeV}$ to the larger energies. The mean atomic number $\langle\mathrm{Z}\rangle$ for the studied granites according to table 1 is 11.452 .

\subsection{Build-up Factor}

The values of $(\mu / \rho)$ and $\left(\mu_{\mathrm{b}} / \rho\right)$ are employed to determine the build-up factor B according to equation (2), Table 2 where the values of the mass attenuation coefficients are the measured broad beam value and the theoretical value from XCOM, [15, 19]. Table 3 lists the obtained values of B.

Table 3. The build-up factor for Double Black, Rose Al-Howdy and Bianco Halayeb granites.

\begin{tabular}{llll}
\hline $\mathbf{E}_{\boldsymbol{\gamma}}(\mathbf{M e V})$ & $\mathbf{B}$ DB & B RH & B BH \\
\hline 0.081 & 1.105 & 1.076 & 1.074 \\
0.356 & 1.008 & 0.989 & 0.987 \\
0.662 & 1.004 & 1.006 & 1.012 \\
1.173 & 1.005 & 1.009 & 1.010 \\
1.332 & 1.011 & 1.007 & 1.007 \\
\hline
\end{tabular}

General trends for the build-up factor B show that B has largest values at $\mathrm{E}_{\gamma}=0.081 \mathrm{MeV}$, drops to get no scattering build-up $(\mathrm{B} \cong 1)$ at $\mathrm{E}_{\gamma}=0.356 \mathrm{MeV}$ then $\mathrm{B}$ is recovered to slightly exceed unity at larger energies. As mentioned above, the granites studied have thicknesses in the range $1.8-1.9 \mathrm{~cm}$, which corresponds to $\cong 0.2$ mean free path, $\mathrm{mfp}$ of the $0.356 \mathrm{MeV}$ photons. This thickness can, consequently, be considered as the depth of maximum absorbed dose for this photon energy. At $\mathrm{E}_{\gamma}=0.081$ and $0.356 \mathrm{MeV}$ the $\mathrm{B}$ factor is relatively large at $\mathrm{DB}$ with comparison to $\mathrm{RH}$ and $\mathrm{BH}$. The experimental errors at $\mathrm{E}_{\gamma}>0.356 \mathrm{MeV}$ inhibit showing accurate dependence of $\mathrm{B}$ on the elemental composition of the granites. In this 
regard the $(\mu / \rho)$ was studied for low Z-building materials in the energy range $0.661-1.332 \mathrm{MeV}$. [13] It was concluded that the sample thickness can be kept below 0.5 mfp to achieve accurate $(\mu / \rho)$. The minimum of $B$ at the energy $0.356 \mathrm{MeV}$ means that $\left(\mu_{\mathrm{b}} / \rho\right)$ is maximum in this case. This might lead to the conclusion that the photon energy absorbed in the 1.8-1.9 $\mathrm{cm}$ thickness granites $\mathrm{fm}$ $0.356 \mathrm{MeV}$ photons is maximum.

\subsection{Effective Atomic Number}

Table 4 lists experimental and theoretical values of $Z_{\text {eff }}$ as a function of gamma energy for the studied granites, according to the experimental results and equations (3) and (4).

Table 4. Effective atomic numbers for Double Black, Rose Al-Howdy and Bianco Halayeb granites and the Compilation from [19].

\begin{tabular}{lllll}
\hline $\mathbf{E}_{\boldsymbol{\gamma}}(\mathbf{M e V})$ & $\begin{array}{l}\mathbf{Z} \text { eff } \exp \\
\mathbf{D B}\end{array}$ & $\begin{array}{l}\mathbf{Z} \operatorname{eff} \exp \\
\mathbf{R H}\end{array}$ & $\begin{array}{l}\mathbf{Z} \text { eff } \exp \\
\mathbf{B H}\end{array}$ & $\mathbf{Z}$ eff th \\
\hline 0.081 & 12.00 & 12.276 & 11.779 & 11.284 \\
0.356 & 10.951 & 12.207 & 12.558 & 11.749 \\
0.662 & 11.2056 & 11.071 & 10.489 & 11.466 \\
1.173 & 11.247 & 10.757 & 11.502 & 11.472 \\
1.332 & 11.004 & 10.377 & 11.841 & 11.471 \\
\hline
\end{tabular}

It is found that $Z_{\text {eff exp }}$ is maximum at $E_{\gamma}=0.081$ and $0.356 \mathrm{MeV}$. Generally, except a slight decrease with increase in photon energy, the effective atomic numbers $\mathrm{Z}_{\text {eff }}$ for the three granites has no significant change with respect to energy and show consistency with the theoretical values. At the other energies Compton photon interaction dominates, therefore $(\mu / \rho)$ and $Z_{\text {eff }}$ remains almost constant. These results agree with [5], where the variation of $Z_{\text {eff }}$ for eight alloys, over wide ranges of atomic numbers and photon energy, was studied. It was concluded that in all alloys $Z_{\text {eff }}$ increases in the low energy region to a maximum value and becomes independent of energy. Bronze aluminum $(90 \%$ copper and $10 \%$ aluminum) has maximum $\mathrm{Z}_{\mathrm{eff}} \cong 27.6$ at $\mathrm{E}_{\gamma} \cong 0.7 \mathrm{MeV}$. In present results, $\mathrm{Z}_{\text {eff }}$ has maxima $\cong 12$ at $\mathrm{E}_{\gamma} \cong 0.081$.

\subsection{Total Atomic Cross-section}

Table 5 and figure 6 display the experimental and theoretical values of $\sigma_{\mathrm{t}}$ for $\mathrm{DB}, \mathrm{RH}$ and $\mathrm{BH}$ in the energy range $0.081-1.332 \mathrm{MeV}$. Generally, $\sigma_{\mathrm{t}}$ tends to decrease with the increase of photon energy. The rate is rapid at $\mathrm{E}_{\gamma}=0.081-0.356 \mathrm{MeV}$. This result is correlated with the predomination of the photo-electric effect at low values of $\mathrm{E}_{\gamma}$. Consequently, the contribution of the photo-electric cross-section, $\sigma_{\text {photo }}$ to $\sigma_{\mathrm{t}}$ increases at low photon energy. From the XCOM analysis [15], the photo-elctric effect is comparable to Compton contribution at $\mathrm{E}_{\gamma}=0.081 \mathrm{MeV}$ for all granites. At $\mathrm{E}_{\gamma}>0.081 \mathrm{MeV}$, the Compton interaction between the photons and granite atoms prevails. At $\mathrm{E}_{\gamma}>0.356 \mathrm{MeV} \sigma_{\mathrm{t}}$ continues decreasing but with smaller rate. Furthermore, the differences between granites become smaller.
Table 5. Total atomic cross-sections (in barns/atom) for Double Black, Rose Al-Howdy and Bianco Halayeb granites.

\begin{tabular}{lllll}
\hline $\mathbf{E}_{\boldsymbol{\gamma}}(\mathbf{M e V})$ & $\boldsymbol{\sigma}_{\mathbf{t} \exp } \mathbf{D B}$ & $\boldsymbol{\sigma}_{\mathbf{t} \exp } \mathbf{R H}$ & $\boldsymbol{\sigma}_{\mathbf{t} \exp } \mathbf{B H}$ & $\boldsymbol{\sigma}_{\mathbf{t} \text { th }}$ \\
\hline 0.081 & 7.479 & 7.651 & 7.341 & 7.048 \\
0.356 & 3.215 & 3.5847 & 3.687 & 3.449 \\
0.662 & 2.588 & 2.558 & 2.423 & 2.650 \\
1.173 & 1.975 & 1.889 & 2.019 & 2.015 \\
1.332 & 1.813 & 1.709 & 1.959 & 1.897 \\
\hline
\end{tabular}

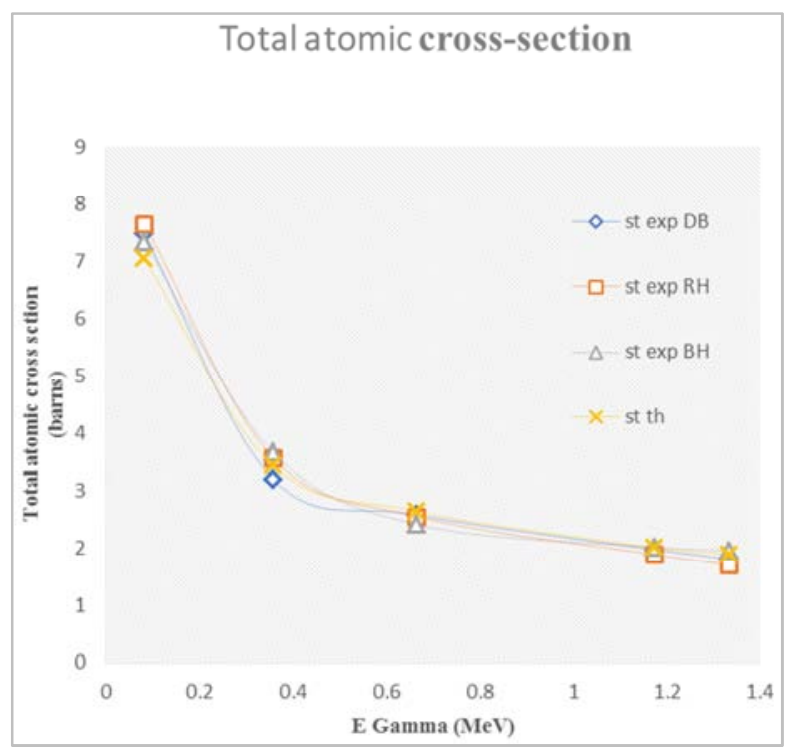

Figure 6. The total atomic cross-section

\section{Conclusions}

Gamma spectrometric parameters of $\mathrm{DB}, \mathrm{RH}$ and $\mathrm{BH}$ granites have been determined from narrow and broad beam geometries. The theoretical mass attenuation coefficients $\left(\mu_{\mathrm{th}} / \rho\right)$ were calculated using the XCOM program based on chemical analysis for granites. The attenuation coefficients decrease with increase in photon energy. The broad beam geometry is more efficient than narrow beam geometry in characterizing the shielding properties of the studied granites. The experimental values of $(\mu / \rho)$ agree, within the experimental errors, with the theoretical values. The $\mathrm{B}$ factor has maximum values at $\mathrm{E}_{\gamma}=0.081$ and minimum values $(\cong 1)$ at $\mathrm{E}_{\gamma}=0.356 \mathrm{MeV}$ then increases slightly over 1 in the studied energy region. The $\mathrm{B}$ factor can't discriminate between the granites. The maximum $Z_{\text {eff }}$ corresponds to minimum $B$ at photon energy $0.356 \mathrm{MeV}$. The enhancement of the photoelectric effect on shielding properties exists in B and $\sigma_{t}$, especially at $\mathrm{E}_{\gamma}=0.081 \mathrm{MeV}$. The total atomic cross-section decreases with increase in photon energy, at the energy region $0.081-0.356 \mathrm{MeV}$.

\section{Acknowledgements}

The authors wish to thank the Physics Department, Helwan University for providing the facilities for this research. 


\section{References}

[1] El-Kateb, A. H. J. Radiat. Prot. and Research. 2018, 43 (2), 75-84.

[2] Limkitjaroenporn, P., Kaewkhao, J., Chewpraditkul, W., Limsuwan, P. Procedia Eng., 2012, 32, 847-854.

[3] Mann, K. S., Singla, J., Kumar, V., Sidhu, G. S. Annals of Nucl. Energy. 2012, 43, 157-166.

[4] El-Kateb, A. H., Rizk, R. A., Abdul-Kader, A. Technical note, Annals of Nucl. Energy. 2000, 27, 1333-1343.

[5] Mudahar, G. S., Singh, M. J. Appl. Radiat. Isot. 1991, 42 (6), 509-512.

[6] Awasarmol, V. V., Gaikwad, D. K, Raut, S. D., Pawar, P. P. J. Radiat. Phys. Chem. 2017, 130, 343-350.

[7] Naydenov, S. V., Ryzhikov, V. D., Smith, C. F. Nucl. Instr. Methods. 2004, B215 (3-4), 552-560.

[8] Rahman, K. N., Abdullah, S. A. King Abdul-Aziz University. 1984, Rep. INIS-mf-12573, 1-96.

[9] Najam, L., Hashem, A. K., Ahmed, H. A., Hassan, I. M. Detection. 2016, 4, 33-39.

[10] Eke, C., Agar, O., Segebade, C., Boztosun, I., Radiochem. J. Radiochem. Acta. 2017, 105 (10), 851-863.

[11] Sakamaki, T., Ohtani, E., Urakawa, S., Suzuki, A., Katyama, Y. Earth and Planetary Science Letters. 2009, 287, 293-297.

[12] Obaid, S., Gaikwad, D. K. Pawar, P. P., Radiat. Phys. and Chemist., 2018, 144, 356-360.

[13] Mann, K. S. Nucl. Inst. and Meth. 2018, A877, 1-8.

[14] Ozyurt, O., Altinsoy, N., Buyuk, B. Acta Physica Polonica. 2015, 127, 1268-1270.

[15] Berger, M. J., Hubbell, J. H., Seltzer, S. M., Chang, J., Coursey S., Sikumar, R., Zucker, D. S., Olsen, K. 2010, NBSIR 87-3597.

[16] Gaikwad, D. K., Pawar, P. P., Selva, T. P. Pramana- J. Phys. 2016, 87, 12-18.

[17] Kurudirek, M., Aygun, M., Erzeneoglu, S. Z., Appl. Radiat. Isot. 2010, 68, 1006-1011.

[18] Levet, A., Özdemir, Y. Rad. Phys. and Chem. 2017, 130, 171176.

[19] Blatt, H., Tracy, R. J., Petrology (2nd Edition). New York, Freeman. P. 1997, 66,. ISBN 0-7167-2438-3.

[20] Wu, F., Jahn, B., Wilde, S. A., Lo, C., Yui, T., Lin, Q., Ge, W., Sun, D. Geochronology and petrogenesis, LITHOS. 2003, 66, 241-273.

[21] Piispanen, R. Bull. Geol. Soc. Finland. 1977, 49 (2), 73-78. 